\title{
As categorias marxistas no pensamento de Preobrazhensky: notas sobre uma teoria de transição
}

Rebecca de Oliveira Freitas ${ }^{1}$

\section{Resumo:}

O presente artigo objetiva avaliar a utilização das categorias de Marx, em especial aquelas desenvolvidas ao longo de $O$ capital, pelo revolucionário soviético Preobrazhensky em sua obra $A$ nova econômica. Analisando a validade da utilização de categorias como mais-valor e mercadoria na URSS da década de 20 do século XX, Preobrazhensky avalia que a lei do valor ainda vigorava então, sendo, porém, combatida pela lei da acumulação socialista primitiva, que impulsionaria o desenvolvimento em direção ao socialismo.

Palavras-chave: capital; transição; acumulação primitiva socialista; Preobrashenky; Revolução Russa.

\section{Marxist categories in Preobrazhensky's thinking: notes on a transition theory}

\begin{abstract}
:
The present paper aims to evaluate the use of Marx's categories, especially those developed throughout The capital, by the Soviet revolutionary Preobrazhensky in his work The new economics. By analyzing the possibility of the use of categories such as surplus value and commodity in the USSR of the 1920s, Preobrazhensky affirms that the law of value still prevailed at the time, but was opposed by the law of primitive socialist accumulation, which would drive development towards socialism.
\end{abstract}

Key words: capital; transition; socialist primitive accumulation; Preobrazhensky; Russian Revolution.

A Revolução Russa foi um dos acontecimentos mais importantes da história do século XX. A partir de outubro de 1917, iniciou-se a primeira experiência de um governo proletário. Seus primeiros anos foram marcados pelas duras contradições imputadas pela destruição do país legada pelos anos de I Guerra Mundial e, entre 1918 e 1921, de Guerra Civil dentro da própria Rússia. Apesar dessas dificuldades, foi um momento de extrema riqueza e de implementação de medidas que caminhavam no sentido da transição para uma sociedade mais justa e livre de exploração e opressão. Podemos citar nesse sentido o processo de radical

${ }^{1}$ Mestre pela Universidade Federal Fluminense (UFF).E-mail: freitasbecca@gmail.com. 
nacionalização e socialização da terra, a nacionalização da produção industrial, bem como a garantia de diversos direitos para as mulheres.

Naquele momento, o impulso para se pensar uma nova sociedade motivava também profissionais de diversas áreas para que repensassem os paradigmas e formatos de produção de conhecimento de forma radical. Em especial no período pós-guerra civil, havia uma grande demanda por traçar um novo rumo para uma economia em colapso, em uma realidade em que as revoltas camponesas e greves se multiplicavam.

Diferentemente da expectativa expressa nos principais escritos de Marx e Engels, e daquilo esperado pelos pensadores marxistas que os sucederam, a revolução explodiu em primeiro lugar na Rússia, um país com uma indústria fraca e pouco desenvolvida e uma agricultura ainda bastante primitiva. Não havia fórmula pronta na teoria marxista a ser implementada pelos revolucionários russos - inclusive por que isso seria contraditório com o próprio método marxista. $\mathrm{O}$ estabelecimento de um governo soviético, baseado sobre a aliança entre trabalhadores e camponeses, que expropriou os proprietários de terra e os capitalistas, socializando a indústria de larga escala colocava desafios sobre as formas de construção do socialismo (DOBB, 1948, p. 177).

Respondendo a esse contexto, os problemas com que os revolucionários russos se depararam na década de 20 do século XX produziram um espaço riquíssimo de debates. As discussões, posições e problemas por eles levantados, longe de ter uma relevância somente histórica e datada, tiveram influência sobre discussões que posteriormente foram travadas por aqueles que buscavam pensar a questão da transição ao socialismo e, em especial, debates relativos ao desenvolvimento em países de terceiro mundo. Temas como o financiamento da acumulação de capital, estratégias de crescimento econômico e industrialização e o papel do campesinato nesse contexto permearam a construção de outros processos revolucionários e estão presentes nos debates econômicos mesmo os não revolucionários - atuais. Vemos, então, a importância do estudo dessa rica produção do período (NOVE, 1965).

Neste artigo nos debruçaremos sobre um debate específico ocorrido ao longo da década de 1920 no seio da vanguarda do Partido Bolchevique. A polêmica, que ficou conhecida posteriormente como "O Grande Debate" versava sobre a melhor forma de articular o setor estatal e privado na reconstrução da URSS pós-guerra civil e dos ritmos de industrialização adequados a tal propósito. De forma geral, é possível apontar dois grandes campos nessa discussão.

O primeiro deles consistia na maioria do partido, a chamada direita, a qual tinha como principal porta-voz em termos de política econômica Bukhárin. Soma-se a ele Stálin, Rikov e, até 1925, também Kamenev e 
Zinoviev. Esse grupo defendia uma política que incentivasse a produção do campesinato. O segundo campo era aquele composto pela Oposição de Esquerda, mais tarde Oposição Unificada. Seus principais protagonistas são Preobrazhensky, no campo econômico, e Trotsky. A ele aderiram Zinoviev e Kamenev em 1925. O tom desse debate era matizado pela disputa interna do partido e se relacionava com temáticas não restritas ao campo econômico, mas pertinentes à transição, como o debate sobre a burocratização, por exemplo.

Dentre os principais sujeitos do debate, a produção de Preobrazhensky tem um aporte interessante. Militante do Partido Social Democrata dos Trabalhadores Russo desde 1903, especificamente associado à fração bolchevique, Preobrazhensky teve participação ativa nas revoluções de 1905 e 1917. Ele participou, a partir de 1917, do Comitê Central do Partido Comunista Russo. Suas posições ao longo do período revolucionário se mantiveram no campo das críticas à esquerda, tendo ele participado do grupo dos Comunistas de Esquerda durante o período do Comunismo de Guerra, e sendo, em 1923, um dos fundadores da Oposição de Esquerda - da qual ele foi um dos principais porta-vozes e formulador no campo da política econômica. Dentre suas obras, podemos citar $O A B C$ do comunismo, escrito em conjunto com Bukhárin em 1919, e Dinheiro na época da ditadura do proletariado, de 1920. Seu trabalho principal, contudo, foi o livro A nova econômica. Publicado em 1926, que elaborou de forma mais sistemática a Teoria de Acumulação Socialista Primitiva do autor. O autor elaborou em seus escritos uma proposta de teoria da acumulação primitiva socialista, resumidamente definida como a constituição de condições materiais e sociais para a reprodução propriamente socialista. Isso se daria pela expansão das relações socialistas (note que não utilizei o termo "estatais") através da destruição das relações capitalistas ou da pequena produção de mercadorias. Isso significava não simplesmente uma proposta de acúmulo de riqueza material, mas de transformação das relações de produção, tanto no setor privado quanto no setor estatal. Algumas leituras feitas sobre o autor reduzem sua teoria a um superindustrialismo e a uma proposta de exploração do campesinato. Consideramos ser essa uma leitura incorreta das propostas formuladas por Preobrazhensky, e suas reverberações nas elaborações da Oposição de Esquerda. Longe restringir seu pensamento a somente o ritmo que a indústria deveria seguir na época, consideramos ser possível visualizar em seus escritos uma proposta de teoria de transição ao socialismo mais complexa. Se isso se expressa de diversas formas na obra do autor, nos parece que um ponto essencial é forma como ele interpreta as categorias elaboradas por Marx. Desta forma, buscamos ao longo deste artigo analisar o tratamento dado por Preobrazhensky às categorias 
marxistas como uma forma de contribuir para a compreensão de sua teoria de transição ao socialismo.

\section{Interpretações sobre a obra de Preobrazhensky}

A obra de Preobrazhensky foi relativamente pouco explorada pelos estudos historiográficos. É possível traçar a existência de três maiores sínteses de sua obra, elaboradas por Alexander Erlich (1950), Richard B. Day (1975) e Donald A. Filtzer (1976). Será feita uma exposição dos pontos de vistas elaborados pelos autores, também incluindo argumentações de outras fontes bibliográficas que tocam em questões mais pontuais da obra de Preobrazhensky.

Alexander Erlich foi o responsável por impulsionar o debate no Ocidente em torno das discussões soviéticas sobre economia ocorridas nos anos 20, a partir de seu livro The Soviet Industrialization Debate, 19241928 de 1960. Ele também possui um trabalho especificamente sobre Preobrazhensky (1950). A tese geral defendida por Erlich é a de que o plano de industrialização e coletivização forçada implementado por Stálin na década de 1930 foi a aplicação prática das teorias elaboradas por Preobrazhensky em um nível extremo. Isto não é sinônimo de afirmar que Preobrazhensky defendesse tais políticas, mas de encontrar em seus escritos elementos que, aprofundados e estendidos, formaram as bases dos planos quinquenais stalinistas.

Os pontos destacados do pensamento de Preobrazhensky por Erlich se relacionam basicamente à industrialização. O autor destaca o papel da industrialização, reposição e ampliação das forças produtivas como forma de garantir um nível de acumulação que evitasse a existência de uma nova "fome de bens" e acabar com o desequilíbrio entre os setores da economia soviética. Erlich situa que a posição apresentada por Preobrazhensky consistia, na verdade em um dilema cuja solução o autor não propunha.

O aumento drástico da propensão ao consumo como resultado da mudança na estrutura de renda pressionada para aumentar a oferta; a condição de deterioração do equipamento e a falta de capacidades de reserva adequadas tornaram esses aumentos impraticáveis, exceto por grandes aumentos no volume de construção do capital; o fator de "complementaridade" tornou ainda mais dramática a magnitude dessa expansão necessária. Mas as mesmas circunstâncias que empurraram para um grande volume de investimento colocaram obstáculos em seu caminho. Assim, a escassez de equipamentos permitiu que o investimento prosseguisse na escala desejada apenas à custa do consumo, enquanto a equalização da renda deixou pouco espaço para que poupanças voluntárias correspondessem ao aumento das despesas de investimento ou para que o consumo de luxo fosse reduzido e qualquer tentativa suficiente para substituir a 
propensão voluntária ao consumo certamente voltaria com efeitos drásticos (ERLICH, 1950, p. 80).

Assim, o impulso à industrialização com foco na produção de meios de produção teria como consequência um gargalo na esfera da produção do consumo. Erlich aponta, ainda, a industrialização implementada pelo stalinismo como uma regra não para o período primitivo do socialismo, mas a essência do socialismo em si - uma diferenciação da ênfase dada por Preobrazhensky.

Richard B. Day escreveu alguns artigos sobre Preobrazhensky (1982; 2014; 1975; 1977). Ele também foi responsável pela tradução de diversos dos escritos do revolucionário russo, com destaque para seu projeto atual dos Preobrazhensky's Papers (2014) que pretende reunir a obra completa de Preobrazhensky. Sua leitura do autor basicamente o situa como um precursor teórico da concepção do socialismo em um só país, apesar da sua participação na Oposição de Esquerda, a qual notadamente se opôs a tal programa. Day sustenta esta leitura a partir da divisão da obra de Preobrazhensky em três momentos: (i) durante o comunismo de guerra; (ii) do início da NEP à 1923; e (iii) de 1923 em diante, incluindo aqui sua capitulação ao stalinismo.

O primeiro momento teria como característica a afirmação de que a avaliação do sucesso do período de transição se daria a partir do crescimento da quantidade de produtos - não mercadorias - que passam pelo estado proletário. Para Day, esta foi uma tentativa de Preobrazhensky de utilização da teoria de Marx que esbarra nas diferenças da realidade da Rússia revolucionária em comparação ao mercado capitalista completamente desenvolvido cuja crise originaria as possibilidades do planejamento econômico. Ainda assim, Day destaca que Preobrazhensky, ao reconhecer o fato de que o dinheiro continuaria tendo um papel limitado enquanto houvessem pequenos produtores de mercadoria voltados para o mercado local, situa isto como uma política da acumulação socialista primitiva, onde o dinheiro representava a abertura da possibilidade de trocas desiguais com o setor privado.

O livro Da NEP ao socialismo seria o marco do início do segundo período da obra de Preobrazhensky para Richard Day. A caracterização dada por Day da obra aponta o fato de que, Preobrazhensky, ao não ter esperanças no mercado mundial como fonte de auxílio econômico para o desenvolvimento da URSS (fosse na figura de empréstimos ou comércio), teria adaptado sua teoria para o desenvolvimento das forças produtivas no interior da própria URSS. Nesta obra, o autor afirmaria que o desenvolvimento industrial não dependeria de mercados externos e que os vastos recursos possuídos pela Rússia lhe dariam a possibilidade de se desenvolver em um organismo econômico autossuficiente. Day afirma que 
a obra representou, também, uma inovação metodológica na abordagem do autor. Seus escritos monetários até então apontariam para a transição essencialmente como um salto não dialético para o comunismo. Da NEP ao socialismo, contudo, incorporaria a compreensão de Lênin da NEP enquanto uma unidade de opostos.

A mudança na argumentação de Preobrazhensky teria se dado a partir de 1923. A publicação do artigo A Lei fundamental da Acumulação Socialista, em 1924, e que seria posteriormente incluído em sua obra $A$ nova econômica (1979) publicada em 1926, seriam as obras chaves desta mudança. Ela, contudo, não significa uma ruptura por completo com a fase anterior. Na verdade, Day considera que metodologicamente $A$ nova econômica seria uma elaboração em termos mais sofisticados da abordagem Da NEP ao socialismo. Aqui a economia soviética seria, também, retratada como uma unidade dialética de planejamento e mercado. As duas leis reguladoras da economia estariam em constante conflito e seria papel dos governantes soviéticos entenderem a interação entre estas leis e prever e evitar as dificuldades do período de transição. Se em termos metodológicos Day traça uma continuidade entre estas duas obras, ele situa uma ruptura na questão temática. A ênfase da Nova Econômica é sobre a necessidade de superar o desequilíbrio entre a indústria e a agricultura através de um sistema de trocas desiguais para o sucesso da transição. Isto levaria a uma compreensão de Preobrazhensky de uma transição ao comunismo em termos de três etapas claramente definidas, um acréscimo quando comparado à produção de Marx, que previa somente duas. Day considera que tal inclusão se relaciona ao fato de a revolução ter ocorrido em um país isolado e tecnologicamente atrasado. Encontra-se uma posição semelhante à de Day também em Papagotiou e Sotiris (2017), que caracterizam a posição de Preobrazhensky como uma versão menos extremada das ações de Stálin na década de 30.

Finalmente, Donald Filtzer escreveu sua tese de doutorado sobre a teoria da reprodução ampliada em Preobrazhensky. Em seu trabalho, o autor critica Alexander Erlich por considerar que Preobrazhensky teria chegado a uma contradição insolúvel quando em 1927 concluiu que o desenvolvimento autônomo do socialismo na URSS seria impossível, dependendo de uma revolução no Ocidente. Por outro lado, ele também critica Richard Day e sua compreensão de que Preobrazhensky teria se acomodado à teoria do socialismo em um só país. A crítica geral que ele faz a ambos os autores é que eles dissociam o aspecto econômico do pensamento de Preobrazhensky, tanto de suas metodologias e de seus objetivos com sua teoria. Ele defende, então, que não é possível entender a obra de Preobrazhensky a partir de categorias burguesas. Tampouco podese entendê-la reduzindo o debate dos anos vinte à industrialização, 
igualando socialismo à industrialização. Não levar estas questões em consideração levaria a uma visão tecnicista e unilateral de Preobrazhensky, segundo o autor. Filtzer destaca três pontos balizadores para compreender a teoria de transição de Preobrazhensky: o conceito de dois reguladores, seu entendimento de consciência de classe e a impossibilidade do socialismo em um só país.

Preobrazhensky já traria a questão dos reguladores conflitantes desde 1921, e demonstraria em seus escritos que a lei do valor não só existia como prosperava na URSS, influenciando até o próprio setor estatal. A única forma de se subordinar a lei do valor expressa na produção privada seria através do mercado - o espaço em que se encontravam. Assim, os métodos de subordinação, como as trocas desiguais, por exemplo, seriam adaptações à estrutura da economia privada - fosse ao mercado interno ou ao mundial. Contudo, o controle político estatal alteraria a essência destes processos que manteriam a forma capitalista, mas desenvolveriam um conteúdo distinto, voltado para o avanço da economia estatal. $\mathrm{O}$ conflito das leis também se daria dentro do próprio setor estatal. Para todos os efeitos, a solução era o planejamento.

Filtzer aponta que é possível reconhecer nos escritos de Preobrazhensky uma explicação sobre o surgimento da burocracia, um estrato não proletário dentro da economia e do aparato estatal que teria sua base material nos elementos capitalistas da economia estatal.

Assim, se encontra sob a lei da acumulação socialista não só o conflito do proletariado e os grupos sociais capitalistas, mas também entre o proletariado e a burocracia, embora não chegue ao ponto de igualar a burocracia à burguesia.

Filtzer considera que Preobrazhensky dá uma primazia analítica para a organização do trabalho humano. Neste sentido, seria equivocado considerar que o desenvolvimento econômico puro e simples garantiria a abolição dos vestígios do capitalismo durante o período de transição. A riqueza material e o desenvolvimento técnico tornariam isto possível, e só.

Mais do que isso, Preobrazhensky consideraria que o desenvolvimento da indústria estatal era limitado por fatores não só econômicos, mas também pelo nível de cultura da população em geral e da classe trabalhadora em particular.

Filtzer considera, assim, que a partir de um entendimento das forças produtivas como englobando os meios de produção e o proletariado, como um agente ativo, a tônica do debate da industrialização seria outro.

Em outras palavras, a necessidade de uma revolução no ocidente era a conclusão inexorável não só da análise política geral de Preobrazhensky e da Oposição de Esquerda, mas da sua análise econômica específica das condições da reprodução ampliada sob condições soviéticas (FILTZER, 1976, p. 11). 
Sem essa relação, a disputa entre a oposição de esquerda e o stalinismo se reduz a questão a um debate sobre política econômica, quando ela na verdade abrange outros pontos. Aqui podemos identificar a questão democrática, a qual também se relaciona com o debate de consciência e cultura proletária. Desta forma, a elaboração de Filtzer considera que a defesa do programa de industrialização proposto por Preobrazhensky só pode ser compreendida à luz do debate sobre consciência de classe e democracia, um combate à burocratização e a defesa do internacionalismo como condições para a reprodução ampliada no setor estatal.

\section{Preobrazhensky e A nova econômica}

Como já citado, A nova econômica foi a principal obra de Preobrazhensky. O projeto original do livro incluía dois volumes. O primeiro, que foi parcialmente publicado, se debruça sobre questões teóricas e o segundo conteria um debate histórico, debates sobre a realidade na URSS e uma apreciação das ideias socialistas e comunistas sobre o socialismo. A edição de que dispomos seria a primeira parte deste primeiro volume. A segunda parte trataria especificamente da história da teoria socialista, objetivo parcialmente completado em dois artigos publicados por Preobrazhensky sob o nome Concepções socialistas e comunistas do socialismo, os quais só estão disponíveis em russo. Além do conteúdo desses artigos, a segunda parte deste volume pretendia ter também conteúdo sobre Lênin e os bolcheviques - parte que nunca foi escrita.

O segundo volume nunca chegou a ser publicado, embora parte do seu conteúdo esteja presente em artigos publicados separadamente. Três artigos sobre o equilíbrio econômico sob o capitalismo concreto e sob o sistema soviético foram publicados em 1926 e 1927, os quais têm tradução disponível em inglês. Esses artigos seriam a parte 1 do volume II, constituindo a parte teórica deste volume, que tinha como objetivo fazer uma análise concreta da economia soviética - contendo, em sua segunda parte, equações algébricas dos esquemas de reprodução discutidos teoricamente na parte 1. Essa segunda parte nunca foi escrita.

Da primeira parte do primeiro livro, trechos já haviam sido publicados em artigos separados anteriormente - o segundo e o terceiro capítulos do livro já haviam sido impressos no Mensageiro a Academia Soviética. A menção nesses artigos da Teoria de Acumulação Socialista Primitiva constituiu um ponto importante do debate entre a direita e a Oposição de Esquerda do partido ao longo da década de 1920 sobre questões relacionadas ao ritmo de industrialização e a relação com o 
campesinato, engendrando uma discussão mais ampla sobre a transição ao socialismo.

Ao longo do livro, Preobrazhensky faz uma interpretação original e bastante interessante sobre a possibilidade de utilizar as categorias de Marx para a análise de uma sociedade socialista, e mais especificamente de uma economia mercantil-socialista, ainda em transição ao socialismo, como a URSS da década de 20. A discussão do livro A nova econômica, assim, constitui um interessante estudo sobre a forma como os intelectuais soviéticos interpretaram a obra de Marx - mais especificamente as categorias elaboradas pelo autor ao longo dos três livros de $O$ capital.

Em primeiro lugar trataremos da questão do método em Preobrazhensky, o qual é uma temática destacada pelo próprio autor. $\mathrm{O}$ primeiro capítulo é, inclusive, intitulado Sobre o método de análise Teórica da economia soviética. Esse capítulo, longe de se restringir a uma discussão completamente teórica sobre metodologias propõe o seu debate em relação à análise do concreto. Isso se relaciona justamente à metodologia marxista, da qual o autor parte, que não traz as categorias prontas para encaixá-las na realidade, mas, ao contrário, analisa a realidade para a elaboração de categorias abstratas.

Donald Filtzer (1976), em sua tese sobre a reprodução ampliada em Preobrazhensky, aponta a importância que a compreensão da natureza das categorias marxistas tem para a leitura da obra do autor. Segundo ele, a teoria de Preobrazhensky da acumulação socialista primitiva depende necessariamente da premissa de que as categorias de análise são transitórias historicamente e representações ideais de tipos específicos de relações sociais.

Na Introdução de 1857 aos Grundrisse (MARX, 2011), Marx trata da questão do método de análise da realidade. Nesse texto, ele critica a forma como os economistas políticos até então construíram as categorias, e destaca a sua historicidade. Já no primeiro item da introdução, quando aborda a questão da produção em geral. Ele aponta que a noção de "produção em geral" seria uma abstração racional na medida em que reconhece elementos comuns às diversas épocas históricas, mas que só teria alguma utilidade se não apagasse a especificidade desses momentos.

As determinações que valem para a produção em geral têm de ser corretamente isoladas de maneira que, além da unidade decorrente do fato de que o sujeito, a humanidade, e o objeto, a natureza, são os mesmos -, não seja esquecida a diferença essencial (MARX, 2011, p. 41).

Marcello Musto afirma que no texto da Introdução de 1857, Marx daria mais um passo na formulação de seu método de elaboração de categorias abstratas, porém históricas, para análise da realidade concreta, diferentemente de outros momentos de sua obra. 
Então a abstração ganhou uma função positiva para Marx. Não era mais, como em sua crítica anterior de G. W. F. Hegel, sinônimo de filosofia idealista e de substituição da realidade, ou, como ele colocou em 1847 na Miséria da filosofia, uma metafísica que transformava tudo em categorias lógicas (MUSTO, 2008, p. 6, tradução da autora).

A historicidade das categorias era essencial para Marx pois, se havia elementos comuns à produção em geral - é necessário haver pessoas e materiais para haver produção, por exemplo - é o particular de cada época histórica que permite de fato conhecê-la.

Se a abstração não for combinada com o tipo de determinações característica de qualquer realidade histórica, então a produção deixaria de ser um fenômeno específico e diferenciado para ser um processo perpetuamente idêntico a si próprio, o qual ocultaria a "diversidade essencial" [wesentliche Verschiedenheit] das formas variadas através da qual ele se manifesta (MARX apud MUSTO, p. 7, tradução da autora).

Esse elemento também se revela em sua crítica aos economistas políticos que, ao falar da produção em geral, naturalizavam e universalizavam elementos próprios do modo de produção capitalista. Parecia ser próprio da produção em geral, por exemplo, a existência do capital. O autor aponta a conveniência de negar a historicidade da categoria capital, visto que isso retira a necessidade de se refletir sobre sua origem e tratar do sangrento processo de acumulação primitiva.

Ao retratar o trabalho assalariado como uma relação universal, e não como uma realidade história determinada, os economistas políticos incorriam em consequências epistemológicas, mas também políticas. Essa compreensão implica que a exploração e alienação sempre existiram e sempre existirão.

Filtzer (1976) aponta que a naturalização de categorias é uma consequência da fetichização das relações sociais, que aparecem como coisas cristalizadas.

É só através da tradução do trabalho humano concreto em valor, em valor abstrato e alienado que tenha tido suas características concretas e úteis completamente apagadas dele e seja assim comum a todos os produtores, que a troca, como sine qua non da produção capitalista, pode existir. $\mathrm{O}$ ato da troca requer e pressupõe que relações diretas entre produtores sejam abolidas e que toda produção e relações sociais sejam mediadas através de coisas. Consequentemente, essas relações se tornam objetificadas na consciência humana precisamente por que elas se tornaram objetificadas na vida social (FILTZER, 1976, p. 26).

Filtzer também cita Rubin, para se referir às categorias econômicas marxistas. Estas expressariam relações de produção entre as pessoas e são, portanto, localizadas historicamente. 
As categorias econômicas expressam relações de produção diferentes entre as pessoas e funções sociais que correspondem a elas, ou as formas social-econômicas das coisas. Essas funções ou formas tem um caráter social porque elas são inerentes, não às coisas em si, mas às coisas que são partes de um ambiente social definido, notadamente coisas através das quais as pessoas entram em relações de produção determinadas umas com as outras. Essas formas não refletem as propriedades das coisas, mas as propriedades do ambiente social (RUBIN apud FILTZER, 1976, p. 32).

Somamos às citações já elencadas acima, um trecho do próprio Preobrazhensky, retirado do terceiro capítulo da Nova Econômica, que demonstra seu tratamento dessas categorias.

O que denominamos de categorias da economia política são descrições logicamente puras, ideais das relações reais de produção, troca e repartição que se estabelecem com base na produção mercantil e mercantil capitalista. (...). É a descrição científica desses tipos de relações de homens entre si (e não de coisas entre si ou de homens entre coisas), a partir da produção mercantil e mercantil capitalista que Marx designa por categorias da economia política; estas categorias consequentemente, descrevem adequadamente as relações reais quotidianas do capitalismo mas, na ciência, essas relações são reproduzidas de modo abstrato, sob sua forma pura (PREOBRAZHENSKY, 1979, pp. 168-9).

Posto que as categorias marxistas são históricas, se referindo à análise do capitalismo, Preobrazhensky encontra dois problemas sobre que método usar para analisar a economia soviética, os quais se referem à diferença do objeto encontrado por ele daquele analisado por Marx, o capitalismo clássico. Essas diferenças são a existência de um capitalismo em decadência e de um novo sistema econômico.

Preobrazhensky expõe o método da economia de Marx enquanto altamente abstrato, sendo sua primeira abstração aquela da estrutura da superestrutura.

O marxismo começa a análise a partir do centro evolutivo de todas as modificações e de todo movimento, quer dizer, a partir da economia, separando-a de todo o resto, num momento determinado do estudo, pela força da abstração (PREOBRAZHENSKY, 1979, p. 52).

Haveria ainda, contudo, a necessidade de um segundo nível de abstração, feito em cima da estrutura já abstraída da superestrutura, de reconhecimento das leis de funcionamento do capitalismo a partir de um conceito puro do capitalismo. A partir dessa abstração, ficariam claras as particularidades desta estrutura econômica que exigem um método analítico abstrato adequado para estudá-las, diferente de uma metodologia geral sociológica. O primeiro movimento de abstração consistiria na 
utilização do materialismo dialético em geral, como o método sociológico universal de Marx. Já o segundo apontaria para a elaboração das categorias próprias à análise do capitalismo.

O autor então situa que a análise de um sistema em que a essência das coisas e sua manifestação não coincidem só poderia ser feita a partir de uma análise crítica e abstrata da lei do valor. Para a análise marxista do capitalismo, assim, seria necessário o método dialético abstrato bem como do conceito de lei de valor - este segundo ponto seria uma diferença para a análise de sociedades nas quais a lei do valor ainda não regula ou não mais regula.

Assim, dada a alteração do objeto de estudo, que deixa de ser o capitalismo para ser uma sociedade de economia socialista mercantil, e dada a historicidade das categorias marxistas, Preobrazhensky propõe a substituição da economia política, adequada para a análise do capitalismo, pela noção de tecnologia social.

Mas se, no domínio da realidade econômica, a mercadoria do modo de produção capitalista é substituída, na economia planificada, pelo produto; se o valor é substituído pela medida do tempo de trabalho; se o mercado (enquanto domínio de manifestação da lei do valor) é substituído pela contabilidade da economia planificada; se a mais-valia é substituída pelo sobreproduto, do mesmo modo, no domínio da ciência, a economia política é substituída pela tecnologia social, isto é, pela ciência da produção social organizada. (PREOBRAZHENSKY, 1979, p. 55).

O autor afirma que a economia política, segundo Marx, não seria uma tecnologia social, pois estuda apenas as relações de produção de uma forma de economia espontânea e não organizada, com os tipos de regulação que são inerentes somente a esta forma, isto é, os tipos de regulação que se manifestam com base na lei do valor. A lei do valor imporia limitações ao planejamento, mesmo que os agentes estivessem delas cientes.

Preobrazhensky passa a se perguntar, então, o que teria mudado no objeto de estudo. No caso de uma sociedade de produção socialista plenamente organizada e planificada, ele afirma que ainda haveria a submissão das atividades dos homens à necessidade e suas relações sociais estariam subordinadas a leis. Obviamente a regulação não se daria mais a partir da lei do valor, como no capitalismo, mas haveria ainda um tipo de regulação. Ele dialoga com críticas recebidas a sua defesa de chamar a regulação dentro de um regime socialista de lei - no caso a lei de acumulação socialista primitiva. Para rebater tais críticas, ele cita trechos do Anti-dühring de Engels, parte dos quais repetimos aqui.

As leis de sua própria atividade social que, até o presente, levantavam-se contra os homens enquanto leis da natureza, 
estranhas a eles e os dominando, são a partir de agora aplicadas e dominadas pelos homens plenamente conscientes. (...)

A liberdade consiste unicamente nisto: o homem social, os produtores associados, regulam de modo racional suas trocas com a Natureza e as submetem a seu controle coletivo, em lugar de se deixar dominar por elas como uma força cega (...). Mas este domínio continua o da necessidade. É além dela que começa este desenvolvimento das energias humanas que constitui um fim em si mesmo o verdadeiro reino da liberdade, mas que só pode desabrochar sobre a base deste império da necessidade. (ENGELS apud PREOBRAZHENSKY, 1979, pp. 57-8)

Preobrazhensky destaca que não se fala de supressão das leis da atividade social dos homens, só que a lei do valor deixa de existir. A característica fundamental das leis que regulam os regimes socialistas e comunistas seria a sua adaptação e utilização pelos homens.

É nisso que consiste a diferença entre as leis da produção capitalista e as regulações econômico-sociais da economia socialista planificada. $\mathrm{O}$ determinismo domina aqui também mas são diferentes as formas da dependência e as formas da causalidade (PREOBRAZHENSKY, 1979, p. 59).

Um exemplo que ele cita para ilustrar essa diferenciação é o de um hipotético aumento da demanda de calçados em uma sociedade socialista. Ele aponta que, ao contrário do capitalismo, onde isso só poderia ser verificado à posteriori, pela prova do mercado, na sociedade socialista isto seria previsto de antemão. Ainda que ele componha, assim, o planejamento, o aumento das necessidades seguiria sendo um fato objetivo - seja pelo aumento populacional ou pelo cálculo da durabilidade dos sapatos existentes, por exemplo, o qual não resulta de uma variação decorrente da influência consciente da própria sociedade visando a substituição de um tipo de calçado por outro e a produção não acarreta deliberadamente novas demandas. Assim, sob o socialismo, a regulação não se impõe por intermédio do mercado. A presença da regulação se apresenta não à posteriori, como no capitalismo, mas se manifesta previamente com o conhecimento dos organismos econômicos reguladores da sociedade (PREOBRAZHENSKY, 1979, p. 61). Esta antecipação do processo regido por leis constitui justamente o primeiro traço característico da produção socialista, da nova produção, traço que a distingue da antiga.

Em segundo lugar, a dependência mútua das diferentes partes do mecanismo de produção também se faz sentir não de modo espontâneo, mas sim como parte do planejamento elaborado pelo estado soviético, a 
partir da figura da Gosplan². Disso decorre que as possibilidades de utilização da força de trabalho e dos recursos naturais existentes são maiores do que aquelas presentes sob as condições apresentadas pelo capitalismo, já que seu planejamento em conjunto permite a organização de diversas combinações não possíveis pela anarquia capitalista. Isso significa que, a partir de uma mudança qualitativa, abre-se a possibilidade para um aumento quantitativo da produção.

Essas diferenças seriam, portanto, a justificativa da impossibilidade de se trabalhar meramente com o arsenal teórico forjado pela economia política fazendo com que, com a mudança do objeto, também se tornasse necessário mudar as categorias de análise a ele vinculadas.

Com o desaparecimento da lei do valor da realidade econômica desaparece igualmente a velha economia política. Uma nova ciência ocupa agora o seu lugar a ciência da previsão da necessidade econômica numa economia organizada, a ciência que - no campo da produção ou em outro - visa obter o necessário do modo mais racional (PREOBRAZHENSKY, 1979, p. 62).

Quando falamos da realidade soviética daquele momento, contudo, estamos falando não de um sistema socialista puro, mas de um momento de transição. Nesse momento, coexiste um princípio de planificação com a lei do valor. Para analisá-las, ele destaca o fato de que a mera descrição dos fenômenos não seria suficiente, sendo necessário usar o método analítico abstrato, o qual já foi apresentado neste texto, sobre esta realidade para revelar os aspectos puros das tendências que se enfrentam. Enquanto sobre a lei do valor já haveria uma vasta produção, Preobrazhensky aponta a dificuldade de tratar da lei de acumulação socialista primitiva - e é isso que ele passará a explorar então.

O primeiro questionamento proposto pelo autor é se seria correto falar da existência de uma lei de acumulação socialista primitiva ao invés de simplesmente se referir a um princípio de planificação e sua implementação prática. Falar especificamente dessa temática também é uma resposta às críticas recebidas pelos artigos que ele havia publicado anteriormente sobre o tema - ele trata dessas críticas e de sua resposta a elas brevemente também no prefácio dessa obra. As objeções que tratavam da questão das duas leis em funcionamento na economia soviética revelariam, para Preobrazhensky, uma concepção naturalista e a-histórica da lei valor, a qual seria vista como a reguladora dos gastos com mão de obra em geral, em qualquer sistema social, ao invés de específica ao regime mercantil capitalista. Além disso, ao afirmarem que a lei do valor seria a única em vigência na URSS, seus opositores teriam negado o caráter

2 A Gosplan era o órgão responsável pela elaboração do planejamento econômico soviético, notadamente dos planos quinquenais. 
socialista da economia soviética - aqui Preobrazhensky faz uma ressalva de que esse caráter ainda poderia ser considerado bastante primitivo - e negado também a existência de uma luta na economia soviética entre tendências da economia mercantil e as tendências do desenvolvimento socialista. Essa concepção, para ele, se aproxima daquela defendida pelos mencheviques.

Uma outra abordagem dessa mesma objeção se centra sobre o reconhecimento da existência de uma luta entre o princípio de planificação contra o mercado, mas a impossibilidade de se afirmar a existência de uma luta da lei do valor contra uma lei da acumulação socialista primitiva - ou seja, o problema aqui é a utilização do conceito de lei. Ele questiona esse aspecto da crítica afirmando que, sob essa interpretação, a lei da acumulação socialista primitiva se reduziria à lei do Sovnarkom (Conselho de Comissários do Povo). Esses críticos que afirmam a existência da lei do valor, ou seja, de uma regulação objetiva da economia mercantil, ao negar a existência de uma regulação objetiva ao processo de reprodução ampliada do estado soviético negariam também a possibilidade de uma análise científica dessa realidade, a partir de critérios de causalidade de determinações.

O autor defende a utilização do conceito de lei, retomando seu sentido sociológico geral - "uma repetição das consequências quando da reprodução de causas relativamente semelhantes numa conjuntura social que é relativamente a mesma" - e em seu sentido econômico - "uma repetição das consequências que decorre da reprodução de um tipo determinado de relações de produção" (PREOBRAZHENSKY, 1979, p. 64). A essas definições, ele soma a necessidade de, em um momento de transição, haver um esforço consciente para a constituição de um novo tipo de relação de produção.

Todo o conjunto de tendências conscientes e semiconscientes, dirigidas para o desenvolvimento máximo da acumulação socialista primitiva, constitui justamente esta necessidade econômica, esta lei coercitiva da existência e do crescimento de todo o sistema, que pressiona incessantemente a consciência do conjunto dos produtores da economia estatal e os conduz ainda e sempre a repetir as ações dirigidas para a realização do ótimo de acumulação numa conjuntura dada (PREOBRAZHENSKY, 1979, p. 66).

No caso da transição socialista, as tarefas que se incluem nessas tendências conscientes e semiconscientes incluem uma continuação da reprodução ampliada das relações socialistas, a extensão dos meios de produção que pertencem ao governo proletário, a união de um número sempre maior de operários em torno desses meios, o aumento da produtividade do trabalho em todo o sistema e a reprodução ampliada do sistema. 
Ainda assim, o autor destaca mais uma vez o caráter determinado dessas ações conscientes. Por exemplo, o aprofundamento do trabalho de planificação imposto à economia coletiva é visto como uma lei externamente coercitiva, ele é necessário dentro desse regime, e não somente uma decisão voluntária de seus membros - a elaboração do primeiro plano quinquenal pela Gosplan é citada como um exemplo. Essa lei de regulação dita certas proporções para a organização no interior da economia estatal - há um mínimo necessário para a reprodução ampliada que é imposto de modo coercitivo para sua resistência.

Desconhecer a existência desta lei, ignorar que ela tem um caráter coercitivo para a economia estatal e que influi sobre a economia privada, constitui não somente um erro teórico, uma obstinação mental e um conservadorismo, mas uma coisa perigosa na prática, em termos da luta pela existência de todo nosso sistema econômico coletivo. (PREOBRAZHENSKY, 1979, p. 77)

Isso leva Preobrazhensky a destacar o essencial papel do planejamento dentro da economia soviética. Isso é uma justificativa a seu próprio esforço teórico, pois ele afirma que

Entre nós, onde existe a economia estatal centralizada do proletariado, e onde a lei do valor está limitada e parcialmente substituída pelo princípio do planejamento, a previsão desempenha um papel absolutamente excepcional em comparação com a economia capitalista e, os erros de previsão podem ter, em razão da administração centralizada da economia, consequências mais graves do que os erros dos dirigentes das empresas privadas [...] a teoria aparece como o único meio seguro, e o mais democrático, que assegura a todos os trabalhadores uma previsão científica no que diz respeito à direção planificada. Daí o papel propriamente produtivo de uma adequada teoria científica da economia soviética. (PREOBRAZHENSKY, 1979, p. 46)

Ele afirma, assim, que a responsabilidade dada à ciência durante o período socialista atinge uma escala desconhecida durante o período capitalista, sendo possível conceder-lhe um papel não só científico, mas também produtivo.

A segunda indagação levantada por Preobrazhensky questiona se seria possível e correto metodologicamente analisar os efeitos da lei sob sua forma pura, abstraindo a política econômica real do governo soviético. Preobrazhensky considera tal fato correto pois esse seria o método de Marx: a análise da economia em primeiro lugar - remetendo ao prefácio da Crítica da economia política, quando trata da questão da estrutura e superestrutura. Ele aponta ainda uma dificuldade acrescida àqueles que procurassem não utilizar o método de abstração no que se refere ao ambiente de um regime especificamente socialista. Isso se dá pelo fato de 
que uma política imposta por pressões externas tem a aparência de uma decisão assumida com toda a liberdade. Isso se refere à própria natureza da sociedade socialista, onde, como já se disse, a reação às determinações da necessidade se dá a priori e não a posteriori. Ao não buscar abstrair as características dessa regulação, portanto, corre-se o risco de englobar tudo dentro da esfera do livre-arbítrio voluntário da tomada de decisões do governo. Se a mudança do objeto obriga a passagem da economia política para a tecnologia social, o momento de transição demanda uma ciência de transição que ainda estaria para ser criada pelos economistas soviéticos. $\mathrm{O}$ método escolhido por Preobrazhensky é, então, fazer a análise separada do setor socialista e do setor mercantil da economia soviética, procurando ao fim traçar uma síntese.

A última indagação metodológica feita por Preobrazhensky consiste no questionamento sobre a existência de duas leis em conflito na economia soviética. Se sim, qual delas consistiria no regulador único da economia? Sua resposta inicial para isso é que, sim, de fato existem duas determinantes simultâneas - o que não seria nem ao menos uma novidade histórica, visto que os momentos de transição entre modos de produção também teriam comportado a existência de reguladores simultâneos. Essa contradição estaria presente, por exemplo, no interior da própria economia estatal, a qual ao mesmo tempo em que não se trata de uma produção com vistas ao lucro, também não é ainda uma produção com vistas ao consumo dos trabalhadores da economia estatal e, menos ainda, de todos os indivíduos da economia privada. Essa é sua contradição interna, ligada tanto à natureza desta economia como às condições da luta por sua existência e crescimento. Contudo, Preobrazhensky já antecipa aqui o fato de que a contradição entre uma e outra tendência no interior da economia estatal não adquire a forma de um antagonismo entre classes.

\section{A interpretação de Preobrazhensky das categorias marxistas}

A partir dessa reflexão metodológica, Preobrazhensky analisa as características da Lei de Acumulação Socialista Primitiva, apontando sua definição e os métodos passíveis de sua implementação, bem como a ação da Lei do Valor dentro da sociedade soviética. Ao avaliar esta última, ele analisa a possibilidade de utilizar as categorias elaboradas por Marx em $O$ capital, verificando as alterações dos objetos a que elas se refeririam. Essa análise se centra no terceiro capítulo da obra, A lei do valor na economia soviética. Ao longo do texto, buscaremos destacar a forma como o autor interpreta as categorias marxistas e relacionar essa interpretação à sua teoria da transição. Contudo, não é objetivo deste texto apontar os erros de interpretação da teoria marxista empreendidos por Preobrazhensky. Nosso 
objetivo é, a partir do reconhecimento da embocadura de sua interpretação, identificando suas ênfases e faltas, compreender os elementos que compõe a teoria de transição do autor.

Ao tratar dessas categorias e avaliar o quanto elas podem ser aplicadas à realidade soviética, Preobrazhensky afirma que em um sistema de produção socialista planificada desenvolvido há uma substituição da produção mercantil à produção socialista planificada, do mercado à contabilidade da sociedade socialista, do valor e dos preços aos custos de trabalho da produção, da mercadoria ao produto, do mais-valor pelo sobreproduto. Embora o autor trate desses pontos em tópicos diferentes de seu texto, considero ser apropriado observá-los em conjunto para melhor compreender a visão do autor sobre essas categorias. Passaremos, agora, a um exame delas, recorrendo a uma análise daquelas formuladas por Marx quando necessário.

Iniciaremos com a definição de mercadoria para Marx, partindo do primeiro capítulo do Livro 1 de $O$ capital (2013). A mercadoria é, por um lado, algo - seja material ou imaterial - que satisfaz as necessidades humanas, ou seja, um valor de uso. Por outro lado, a mercadoria é um valor de uso produzido para outrem, ou seja, para ser levado à troca no mercado. Um dos pressupostos da existência da mercadoria, portanto, é a existência de uma divisão social do trabalho, como forma de garantir a existência de trabalhos privados, separados e mutuamente independentes para produzirem mercadorias distintas.

Por outro lado, a realização das trocas de mercadorias distintas por seus valores de uso, ou seja, por suas qualidades materiais, demanda algo que lhes dê uma comensurabilidade. Visto a diferença de suas propriedades materiais, Marx aponta que o elemento em comum possuído pelo conjunto das mercadorias consiste no fato de serem elas produtos do trabalho humano, ou seja, "dispêndio produtivo de cérebro, músculos, nervos, mãos etc. humanos" (MARX, 2013, p. 121). Contudo, esses trabalhos úteis, concretos, também são diferentes em suas atividades - o trabalho de um alfaiate é diferente de um trabalho de um pedreiro, por exemplo. A consequência lógica aqui é que, ao se abstrair a concretude dos valores de uso como forma de tentar encontrar-lhes algo em comum, também se abstrai a concretude do trabalho realizado para sua produção. Assim, chegamos ao elemento comum às mercadorias que permite a sua mensuração em comum e, assim, sua troca no mercado: o trabalho humano abstrato, medido a partir do tempo de trabalho - saímos do âmbito qualitativo para o quantitativo. Contudo, é importante destacar que esse tempo de trabalho é determinado pela média social do tempo socialmente necessário para a produção de uma mercadoria determinada em um determinado período histórico. Esse caráter social da determinação 
do valor da produção aparentemente independente do produtor privado se relaciona, como veremos mais a frente, ao caráter fetichista da mercadoria.

A mercadoria é, então, a união de valor de uso e valor, sendo que este último é um elemento abstrato que se objetiva em sua representação concreta enquanto valor de troca - alguma outra mercadoria pela qual ele seja trocado. É a contradição entre o valor de uso e o valor de troca que colocam a mercadoria em movimento - a mercadoria tem de deixar de ser um valor de uso perante o vendedor para converter-se em valor, concretamente seu valor de troca.

Marx destaca a forma como a verificação do valor de uma mercadoria determinada se dá sempre de forma relativa a outra, que se torna a expressão física de seu valor abstrato. Nesse caso a mercadoria cujo valor se mede tem a forma de valor relativo, ao passo que aquela em cujo corpo o valor é representado ocupa o papel de valor equivalente. Enquanto em princípio qualquer mercadoria poderia ocupar qualquer uma das posições, desde que cada posição fosse ocupada por uma mercadoria diferente da outra, Marx destaca que historicamente existe uma tendência a que as mercadorias em geral expressem seu valor em uma única mercadoria que se torna, então, a equivalente universal, ou mercadoria dinheiro. Ele destaca que concretamente o ouro foi a melhor mercadoria para cumprir esse papel, por suas características de ter uniformidade, divisibilidade e quantidade limitada. Ele demonstra, assim, como a forma dinheiro tem sua origem, na verdade, na forma mercadoria.

O primeiro capítulo do Livro 1 de $O$ capital (2013), assim como o livro como um todo, tem um alto grau de abstração. Trata-se da definição do conceito de mercadoria a partir de uma abstração de uma realidade histórica determinada - condição que se complexifica nos Livros II e III da obra. Ainda assim, esse grau de abstração já permite vislumbrar elementos importantes para a definição do conceito de lei do valor que regula as trocas no capitalismo. A lei do valor implica que as mercadorias têm sua equivalência dada pela quantidade de trabalho socialmente necessário nelas investido. Contudo, não é assim que elas aparecem para os sujeitos nesse processo envolvidos. Adentramos, então, a temática do fetiche da mercadoria, a qual complexifica a caracterização da lei do valor e também traz elementos para se pensar a transição ao socialismo.

O processo de fetichismo da mercadoria consiste na reificação das relações sociais. As trocas das mercadorias no mercado nada mais são do que a demonstração do caráter social de sua produção, dado pela divisão social do trabalho e pela generalização do trabalho abstrato enquanto medida de valor. Contudo, elas não são vistas como uma relação entre homens, mas como características próprias das mercadorias em si, propriedades naturais dos objetos, existentes independentemente dos 
produtores. Assim, aquilo que são relações entre homens se apresentam enquanto relações entre coisas. Contudo, isso não é sinônimo de uma apreensão equivocada da realidade por parte dos envolvidos, essas relações se apresentam reificadas por que de fato o são.

Os trabalhos privados só atuam efetivamente como elos do trabalho social total por meio das relações que a troca estabelece entre os produtos do trabalho e, por meio destes, também entre os produtores. A estes últimos, as relações sociais entre seus trabalhos privados aparecem como aquilo que elas são, isto é, não como relações diretamente sociais entre pessoas em seus próprios trabalhos, mas como relações reificadas entre pessoas e relações sociais entre coisas. (MARX, 2013, p. 148).

Ao final da sessão em que trata sobre a temática do fetichismo da mercadoria, Marx aponta para como as relações de produção se estruturam e são apreendidas em formas econômicas pré-capitalistas, como a Idade Média, por exemplo, e em uma hipotética associação de homens livres. Essa associação organizaria seu trabalho a partir de meios de produção coletivos e despenderia sua força social de trabalho conscientemente de uma forma unitária. O produto produzido seria um produto social, sendo parte dele usado como meio de produção e outra parte distribuído entre seus membros para o consumo de subsistência. Embora admita a possibilidade de distribuição a partir de critérios diversos, Marx constrói um exemplo em que, em paralelo à produção da mercadoria, a distribuição se desse com base no tempo de trabalho. Nesse caso, as relações sociais são evidentes para os envolvidos, e não reificadas.

A figura do processo social de vida, isto é, do processo material de produção, só se livra de seu místico véu de névoa quando, como produto de homens livremente socializados, encontra-se sob seu controle consciente e planejado. Para isso, requer-se uma base material da sociedade ou uma série de condições materiais de existência que, por sua vez, são elas próprias o produto natural espontâneo de uma longa e excruciante história de desenvolvimento. (MARX, 2013, p. 154)

Esse ponto destacado por Marx é importante para pensarmos as próprias características da lei de acumulação socialista primitiva levantadas por Preobrazhensky, dentre as quais a consciência do planejamento figura entre um dos pontos mais importantes.

Postas as características básicas da mercadoria, é preciso inseri-la dentro da forma capitalista de produção de mercadorias - ou seja, não só de valor, mas de mais-valor - para podermos passar à análise das ideias de Preobrazhensky.

O processo de produção, como unidade dos processos de trabalho e de formação de valor, é processo de produção de mercadorias; como unidade dos processos de trabalho e de 
valorização, ele é processo de produção capitalista, forma capitalista da produção de mercadorias. (MARX, 2013, p. 273)

No quarto capítulo do Livro I de $O$ capital (2013), Marx descreve o processo de formação do capital. Dentro de um contexto onde a produção e o comércio já se encontram desenvolvidos, há uma alteração da forma imediata da circulação de mercadorias, representada pela fórmula M-D$\mathrm{M}$ 3, para o formato D-M-D. O que poderia parecer uma mera mudança formal de ordem é, na verdade, uma alteração do objetivo da circulação ele deixa de ser um valor de uso para ser o próprio valor, na figura de seu valor de troca.

A circulação simples de mercadorias - a venda para a compra serve de meio para uma finalidade que se encontra fora da circulação, a apropriação de valores de uso, a satisfação de necessidades. A circulação do dinheiro como capital é, ao contrário, um fim em si mesmo, pois a valorização do valor existe apenas no interior desse movimento sempre renovado. $\mathrm{O}$ movimento do capital é, por isso, desmedido. (MARX, 2013, p. 228)

A circulação neste formato, contudo, não se justifica caso não haja um acréscimo de dinheiro ao final do processo, ou seja, D-M-D', visto que não haveria sentido em se trocar a mesma quantia de dinheiro pela mesma quantia de dinheiro. Nessa forma de circulação, o valor se torna o sujeito que, ao alterar sua forma, ora como dinheiro, ora como mercadoria, altera sua própria grandeza, valorizando a si mesmo. As particularidades do ciclo do capital do ponto de vista de cada uma de suas formas são exploradas por Marx no Livro II de $O$ capital (2014), mas não serão tratadas aqui. Por ora nos interessa a definição desse processo de valorização e a forma como ele é abordado por Preobrazhensky.

Marx destaca que a arbitrariedade da determinação de preços da parte dos vendedores de mercadorias não pode explicar a existência desse acréscimo de valor ao fim da transação. Há um elemento, ao mesmo tempo dentro e fora da esfera da circulação que garante a existência do capital. Fora, por que a produção do valor se dá na esfera da produção, portanto fora da circulação, dentro, por que se dá a partir do consumo de uma mercadoria específica adquirida no processo de circulação e posteriormente também se realiza a partir da venda da mercadoria produzida no mercado. A mercadoria que tem a capacidade de, através do seu consumo, produzir mais valor do que ela própria vale é a força de trabalho.

Marx destaca, contudo, que para que a capacidade de trabalho se torne uma mercadoria disponível no mercado é necessário que existam

3 Nessa fórmula e nas demais $\mathrm{M}$ representa mercadoria, $\mathrm{D}$ representa dinheiro e D' o representa $\mathrm{D}$ acrescido de um valor $\Delta \mathrm{D}$. 
trabalhadores livres - indivíduos livres em dois sentidos: ser uma pessoa livre para dispor de sua força de trabalho como quiser, inclusive vendendoa, e ser uma pessoa livre de outras mercadorias, restando somente a sua capacidade de trabalho como mercadoria a ser vendida.

Passemos, então, às reflexões de Preobrazhensky sobre essa temática. Ele inicia esse item definindo mais-valor para Marx, traçando algumas condições para sua existência: (i) tem que existir mercadorias, ou seja, valor; (ii) o trabalho humano tem que ser uma mercadoria; (iii) tem que existir um "proletariado, separado dos instrumentos de produção, e uma classe de compradores da força de trabalho, dispondo do monopólio do direito de propriedade sobre os instrumentos de produção" (PREOBRAZHENSKY, 1979, p. 208); e (iv) tem que existir um desenvolvimento da produtividade o suficiente para a garantia de um excedente. O autor traça, então, um resumo do desenvolvimento histórico dessa categoria, levando em conta que em sistemas não capitalistas havia sobreproduto, porém não mais-valor.

Quando passa ao campo da economia soviética, ele considera que há uma atrofia dos elementos da categoria do mais-valor à medida que se desenvolvem as forças produtivas em sua forma socialista. Ele passa, então, à avaliação do quanto cada um dos pressupostos da existência do mais-valor se mantém dentro do regime de transição soviético.

O primeiro pressuposto era a existência de mercadorias é, portanto, de valor. Nesse quesito, Preobrazhensky afirma que está ocorrendo uma transição da mercadoria se tornando produto. Para ele essa transição se daria mais rapidamente no setor estatal da produção de meios de produção. Esse fato tem duas determinantes, uma do campo da produção e outra no campo da circulação. A primeira delas, da produção, afirma que a tendência à elevação da composição orgânica do capital se mantém durante o socialismo, ou seja, há uma tendência a proporção de capital constante crescer relativamente ao capital variável na composição dos meios de produção. Este fato faria com que o setor que produz o capital constante, especificamente o capital fixo, ganhasse uma importância cada vez maior dentro da economia. Daí Preobrazhensky conclui que a diminuição da parte relativa do capital, ou seja, da participação humana na produção caminharia no sentido do fim da produção mercantil.

Mas, dado este fato, o desenvolvimento das forças produtivas deve inevitavelmente implicar um aumento da importância específica da produção de meios de produção e este aumento de modo completamente automático acentua a tendência ao desaparecimento da produção mercantil na economia estatal e, deste modo, mina a categoria da mais-valia. (PREOBRAZHENSKY, 1979, pp. 211-2) 
Ao falar do fim da categoria mais-valor, Preobrazhensky parece, na verdade, estender esse colapso à categoria valor como um todo. Essa é uma visão que apresenta uma compreensão equivocada da teoria do valor de Marx. Para este, como vimos, o caráter de valor das mercadorias não deriva somente do fato de que estas são fruto do trabalho humano valores de uso sempre foram produzidos pela humanidade, sendo o trabalho o seu fato ontológico, segundo o próprio Marx - mas sim que o trabalho humano passa a ser a medida social utilizada para as trocas e passa a regular a produção e circulação como um todo. Assim, o desenvolvimento das forças produtivas não aponta inevitavelmente para o fim do mais-valor, o valor pode ainda regular as relações sociais a partir de outras proporções, nesse caso menores, de sua incorporação em cada mercadoria individual. Essa afirmação de Preobrazhensky carrega um otimismo sobre a técnica, uma certa ideologia do progresso. Ainda que as críticas a ela não sejam completamente eliminadas pela segunda parte de sua argumentação, relacionada ao campo da circulação, há uma complexificação de seu argumento.

Preobrazhensky se pergunta se o produto da produção da indústria estatal pode ser considerado uma massa de mercadorias. Para isso o autor responde que sim, que não e que parcialmente não.

Sim, na medida em que temos o monopólio da produção, apoiado no mercado. Não, na medida em que temos o monopólio da produção pelo próprio setor estatal, conservando somente a forma das relações de mercado no interior deste setor; parcialmente não, na medida em que as tendências do monopólio socialista afetam a economia mercantil, acarretando, em muitos casos a liquidação da concorrência e a transformação da própria essência do mercado de mercadorias (PREOBRAZHENSKY, 1979, p. 212).

Assim, no campo da circulação, a produção estatal é mercadoria na medida em que é produzida para o mercado - deduz-se assim que o mercado ainda é regido pela lei do valor. Ela não é mercadoria quando a relação de troca se dá dentro do próprio setor estatal, onde só a forma de mercado se mantém, mas não seu conteúdo, ou seja, as trocas não seriam reguladas pela lei do valor. Por fim, parcialmente não na medida em que existe o mercado privado na URSS, mas que este não se mantém na sua forma pura, sofrendo influências da esfera estatal. Além disso, Preobrazhensky afirma que, em geral, na economia estatal, o caráter mercantil da produção declina na proporção do aumento da soma absoluta da produção e na proporção que aumenta a planificação e a organização de seu organismo econômico. Nesse sentido, há um reconhecimento do caráter social da lei do valor, e este fato na verdade parece se contradizer com sua primeira afirmação em relação às consequências do aumento da composição orgânica do capital. O aumento da soma absoluta da produção 
e a importância da planificação e organização compõem a definição do autor do período de acumulação socialista primitiva, e também estão presentes no debate proposto por Marx sobre a questão do fetiche da mercadoria.

Seu balanço final é que o mais-valor, do ponto de vista da existência de mercadorias, está em colapso e em grande medida já foi eliminado pelo desenvolvimento das relações socialistas de produção.

Voltemos agora às condições de existência do mais-valor enunciadas por Preobrazhensky. Abordaremos agora a terceira delas e, na sequência, voltaremos à segunda - seguindo a ordem de exposição do autor. Este ponto consiste na existência de exploração entre a burguesia, classe dos proprietários dos meios de produção, e a classe trabalhadora, cuja única mercadoria a ser vendida consiste em sua própria força de trabalho. Preobrazhensky afirma que a superação deste pressuposto da existência de mais-valor se encontra mais avançada do que a questão da produção de mercadorias analisada anteriormente. Sua supressão não foi evolutiva, mas através de saltos. Com a tomada do poder político e econômico pelo proletariado, a consequência é que a classe trabalhadora não poderia explorar a si mesma. Isso contribuiria para que o mais-valor se transformasse em sobreproduto.

Ele reconhece o caráter heterogêneo da classe trabalhadora, com a existência de trabalhadores com função de organizadores e a massa de trabalhadores, cujas remunerações divergem. Contudo, essa heterogeneidade é dentro de uma mesma classe e, mais do que isso, consiste em uma herança do capitalismo recebida pelo novo sistema. Para ele, portanto, a desigualdade material decorrente dessa heterogeneidade não existe devido à estrutura de produção soviética, mas sobrevive apesar dela. Ela desapareceria progressivamente através do

desenvolvimento das forças produtivas da economia estatal, [da] elevação sistemática dos salários, [do] controle, pelo sistema socialista, da instrução geral e técnica da juventude proletária e semiproletária, correlatamente a uma reaprendizagem dos adultos, conduzirão a um rápido aumento dos operários qualificados em relação aos operários nãoqualificados e prepararão uma massa de trabalhadores para as funções de organização que excederá de longe o número de funções de organização e direção. E isto significará a dissolução das diferenças profissionais esclerosadas e a transição gradual a uma verdadeira solução socialista do problema dos organizadores e da massa através de uma aproximação entre ambos, com a transformação das profissões, dos agrupamentos esclerosados das mesmas e únicas pessoas, em funções preenchidas em rodízio, por toda a massa. (PREOBRAZHENSKY, 1979, p. 241) 
De qualquer forma ele reforça o argumento de que, ainda que haja heterogeneidade, setores como os Diretores Vermelhos, por exemplo, não possuíam nenhum monopólio sobre os meios de produção, sendo eles também empregados do estado operário. O crescimento quantitativo das forças produtivas dentro da economia estatal, desde que em um ritmo adequado, garantiria o desenvolvimento no sentido da eliminação dessa heterogeneidade.

Preobrazhensky sai da esfera das relações dentro do proletariado, onde ele chegou à conclusão não haver exploração de uma classe por outra, para se debruçar sobre outras formas de exploração que ainda possam existir na URSS. O primeiro tipo é baseado no fato de que uma fração do sobretrabalho seria destinada à remuneração dos técnicos em uma proporção que ultrapassaria o pagamento do trabalho altamente qualificado. Ele explica essa exploração pelo fato de que o desenvolvimento das relações socialistas seria insuficiente dentro do novo sistema educacional - podemos ver aqui a educação cumprindo um papel de dar as condições para a superação de uma condição de exploração, um dos pressupostos da eliminação do mais-valor. Uma segunda forma de exploração consistiria no fato de que uma fração dos sobreprodutos estatais seria capturada pelo capital privado sob a forma de lucro comercial. Esta exploração se explicaria pelo desenvolvimento inadequado do sistema de distribuição que decorre da socialização dos meios de produção. A terceira forma de exploração consistiria nos interesses dos empréstimos internos cobertos pelo campesinato, nepmen e pequena burguesia, bem como o pagamento eventual de juros de antigos e novos empréstimos estrangeiros. Também se inclui aqui um hipotético mal planejamento da acumulação socialista primitiva, onde a economia privada se apropriaria do excedente do estado em uma maior proporção que este do excedente daquela.

Assim, conclui-se que do ponto de vista da existência de duas classes distintas, de possuidores e não possuidores de meios de produção, não haveria mais a produção de mais-valor - dada a propriedade social dos meios de produção na esfera estatal. Os vestígios da organização da produção capitalista seriam eliminados pelo desenvolvimento da lei da acumulação socialista primitiva, tanto pelo crescimento do setor estatal quanto pela educação e reorganização dos trabalhadores.

Voltemos, agora, ao segundo ponto elencado por Preobrazhensky como uma condição para a existência do mais-valor: a configuração da força de trabalho enquanto uma mercadoria.

Mais uma vez a resposta de Preobrazhensky sobre a existência do mais-valor sob essa perspectiva é sim e não. A força de trabalho seria mercadoria quando se olha para a economia como um todo. O número de 
operários empregados pelo estado é inferior ao empregado pelo setor privado - lembrando que isso inclui, e na verdade é majoritariamente, a agricultura. Ainda assim, mesmo os empregados no setor estatal reproduzem sua força de trabalho empregando a grande maioria de seu orçamento para comprar bens de consumo da produção privada, ou seja, o processo de reprodução da força de trabalho está ligado de modo muito estreito à economia mercantil.

No campo especificamente da economia estatal, o nível do fundo dos salários no seu conjunto é regulamentado pela lei da acumulação socialista primitiva, e não pela oferta e procura por mão de obra. Ainda não se trata absolutamente do sistema de distribuição intrinsecamente inerente às relações socialistas de produção - apenas do começo da preparação das condições prévias a uma tal distribuição, das quais uma das premissas é a separação entre o fundo salarial no seu conjunto e a ação da lei do valor.

Temos novamente aqui um interessante exemplo do fato de que, com a socialização dos meios de produção, certas modificações puramente quantitativas - o desenvolvimento das forças produtivas e da riqueza material na economia estatal intensificam automaticamente o processo de dissolução das categorias da sociedade capitalista. (PREOBRAZHENSKY, 1979, p. 218)

A distribuição dentro do fundo geral dos salários, contudo, se mantém quase inteiramente burguesa, ou seja, a forma do salário continua capitalista. A escala hierárquica de salários se manteria até que a formação de trabalhadores qualificados se adaptasse às relações de produção socialistas da economia estatal - tanto na divisão das profissões quanto nos incentivos burgueses para a produção.

Os incentivos socialistas não caem do céu. Cumpre desenvolvêlos através de uma reeducação prolongada do elemento humano criado na economia mercantil, de uma reeducação no espírito das relações coletivas de produção. (PREOBRAZHENSKY, 1979, p. 218)

Na seção VI do Livro I de O capital (2013), Marx destaca a diferença do pagamento do trabalho e do pagamento da força de trabalho. Ele destaca que a forma salário sob o capitalismo contribuiria para o encobrimento desta relação, por sua fetichização, pois daria a aparência de que o salário paga a atividade trabalho. Marx destaca o fato de que a venda do trabalho em si não faz sentido, visto que

Para ser vendido no mercado como mercadoria, o trabalho teria, ao menos, de existir antes de ser vendido. Mas se o trabalhador pudesse dar ao trabalho uma existência independente, o que ele venderia seria uma mercadoria, e não trabalho. (MARX, 2013, p. 606) 
Além disso, caso o que se vendesse fosse de fato o trabalho, a existência do mais-valor só se explicaria pela troca de não equivalentes. Assim, o salário reflete, na verdade, o valor da força de trabalho que consiste no valor dos itens necessários para a reprodução desta força de trabalho em um contexto determinado. Mais uma vez, contudo, Marx alerta para o fato de a expressão "valor do trabalho" se difundir surge das próprias relações de produção, que têm esta aparência. Desta forma, a forma salário apaga a divisão entre trabalho necessário e mais-trabalho, dando ao conjunto do trabalho a aparência de trabalho pago. Soma-se a isso elementos como a variação do salário quando da variação da duração da jornada de trabalho bem como a diferença individual entre os salários de trabalhadores que executam a mesma função, os quais dão uma contribuição para a visão do salário como o pagamento do valor do trabalho.

Nesta seção, ainda, Marx apresenta as formas do salário por tempo e do salário por peça. Os dois são apresentados como variações desta mesma lógica do salário. Contudo Marx considera que a forma do salário por peça é a mais adequada ao capitalismo, visto facilitar a existência de descontos salariais e de fraudes capitalistas quando da avaliação da qualidade dos produtos, a diminuição do gasto com a supervisão do trabalho, bem como uma facilitação da elevação do grau de intensidade do trabalho - já que esta se torna do interesse pessoal do próprio trabalhador. O salário por peça desenvolveria, ainda, uma individualidade ligada a um "sentimento de liberdade, a independência e o autocontrole dos trabalhadores; por outro lado, sua concorrência uns contra os outros" (MARX, 2013, p. 626).

Preobrazhensky se pergunta então sobre qual seria a forma do salário que melhor corresponderia às condições de trabalho na economia estatal do proletariado durante seu desenvolvimento. Durante o Comunismo de Guerra havia operado o sistema de rações, ou seja, um abastecimento coletivo e uma remuneração coletiva. Esta forma de remuneração, por consistir em uma ruptura brusca e de uma só vez com os estímulos individuais e pequeno-burgueses no trabalho, fracassou. No momento em que ele escreveu o livro, em 1926, imperaria o salário por peça ou salário diário/mensal. Sua defesa consiste em que seria necessário chegar a um método combinado de remuneração individual e coletiva e depois para a remuneração do operário coletivo ao invés do individual.

Assim, o aspecto de transição nesse quesito consiste no fato de o fundo de salários ser comandado pelo princípio da acumulação socialista primitiva. Sendo o fato de a maior parte dos trabalhadores encontrarem-se inseridos em relações de trabalho na esfera privada da produção e as formas salariais ainda espaços de ação da lei do valor. 
A última premissa para a existência do mais-valor elaborada por Preobrazhensky determina a necessidade de existência de um sobreproduto, o qual, com exceção do período do comunismo de guerra, também existe no regime soviético.

Buscando trazer uma síntese entre os fatores enumerados, o autor considera ser melhor designar o excedente que vem para a economia estatal depois de satisfeitas as necessidades de consumo dos operários da indústria estatal de sobreproduto, e não de mais-valor, visto que isso caracteriza não somente o que existe - já que em alguns aspectos o autor aponta que o mais-valor ainda existiria -, mas as suas tendências de desenvolvimento. Em relação à indústria privada continuaria válido tudo que Marx escreveu sobre o trabalho assalariado.

Preobrazhensky aponta a existência de uma contradição entre a lei do desenvolvimento das relações socialistas de produção em geral e aquela da transformação dos salários.

Enquanto lei na qual se expressam todas as tendências conscientes e espontâneas da intensificação do ritmo da reprodução ampliada na economia estatal coletiva, ela aparece, por isso mesmo, como a lei do desenvolvimento das relações socialistas de produção em geral. Mas, por outro lado, enquanto lei de limitação dos salários no interesse da acumulação, ela restringe o ritmo de transformação dos salários em ração de consumo do trabalhador na economia socialista por que - a partir do momento em que os instrumentos de trabalho são socializados - é precisamente a rápida elevação dos salários que conduz tanto à separação entre os salários e o valor da força de trabalho como às premissas materiais de desenvolvimento da cultura proletária, socialista. Esta contradição da lei da acumulação socialista primitiva decorre integralmente de seu caráter historicamente transitório. A tendência à superação da categoria do salário, quer dizer, a tendência ao reforçamento da qualidade socialista das relações de produção entra em contradição com a tendência à extensão quantitativa do domínio da economia estatal e de suas relações de produção sob sua forma atual, isto é, de seu caráter socialista. O próprio termo "acumulação socialista primitiva" expressa este duplo caráter da lei: o adjetivo "socialista" entra em contradição com o substantivo "acumulação" ao qual está ligado não apenas gramaticalmente mas também no seu processo histórico real. (PREOBRAZHENSKY, 1979, p. 221)

O autor, assim, destaca a existência de um aspecto qualitativo e de um quantitativo relacionado à lei de acumulação socialista primitiva. Essa sua afirmação impede que se reduza sua formulação à mera acumulação material quantitativa de capital. Está presente em sua reflexão a necessidade de transformar as relações de produção - nesse caso específico a forma salário e aquilo que ela expressa. O reconhecimento do 
caráter contraditório da transição é um mérito no sentido de negar o mecanicismo, não só na análise do capitalismo, mas na construção de sua superação.

\section{Apontamentos finais}

Um mérito do pensamento de Preobrazhensky é justamente não opor a esfera estatal e a privada como lócus de ação de cada uma das leis de forma pura. Ele aponta que há influência da lei do valor dentro da esfera estatal e que a lei da acumulação socialista primitiva também influencia as relações de mercado. Isso é especialmente relevante, quando olhamos a presença de um debate extremamente economicista naquele período, principalmente nas discussões que seriam desenvolvidas pela III Internacional. Charles Bettelheim (1979), chama esse marxismo da III Internacional de "marxismo estratificado", trazendo relevantes críticas a ele. Em primeiro lugar, há uma identificação mecanicista entre as formas jurídicas de propriedade e as relações de classe, em especial durante a transição. Isso levaria, por exemplo, a igualar a estatização das forças produtivas ao socialismo - ele cita o exemplo de Stálin, em relatório apresentado em 25 de novembro de 1936 ao VII Congresso dos Sovietes da URSS. O segundo ponto de crítica seria o primado do desenvolvimento das forças produtivas, considerado como o motor da história - o exemplo citado para ilustrar esse ponto é o livro de Stálin, $O$ materialismo dialético e o materialismo Histórico, de 1938. Se não se chega ao ponto de negar a luta de classes, essa lógica de argumentação a relega a um segundo plano, eliminando qualquer contradição possível entre as forças produtivas e as relações de produção. Chegamos, assim, a uma compreensão de que a luta de classes é efeito direto e imediato das contradições econômicas, tendo a acumulação de novos meios de produção o papel privilegiado na construção do socialismo, em detrimento da iniciativa dos trabalhadores.

Outro exemplo citado por Bettelheim (1978) é o manual de economia política elaborado por Lapidus e Ostroviatianov. Nesse manual, partir-se-ia do pressuposto de que a propriedade estatal e a planificação fariam desaparecer as relações mercantis e capitalistas, sendo impossível utilizar categorias como preço e salário - negadas de uma forma unilateral, completamente diferente dos debates propostos por Preobrazhensky. Essa forma de caracterizar o processo acabava por reduzir as categorias a formas, e não como a expressão de relações sociais - cujo conteúdo é negado pelo manual.

Tal como se pratica na época da NEP (quer dizer, "de cima para baixo”) a planificação econômica não modifica fundamentalmente a exterioridade dos diferentes trabalhos 
entre si, nem as condições em que participam os produtores imediatos. (BETTELHEIM, 1978, p. 259).

Outro exemplo de uma abordagem economicista da realidade soviética é a expressa em um discurso de Stálin no XIV Congresso do Partido Comunista Russo, ocorrido em 1925:

São empresas capitalistas de estado? Não, não o são. Por quê? Por que nelas não se fazem representar duas classes, mas uma só, a classe operária que, personificada em seu estado, possui os instrumentos e meios de produção e que não é explorada (...). Podem nos dizer que, ainda assim, isso não é o socialismo completo, se se leva em consideração os resquícios de burocratismo que ainda existem nos organismos dirigentes de nossas empresas. Isto é certo. Mas isso não é obstáculo para que a indústria estatal seja, por seu tipo, uma produção socialista. (BETTELHEIM, 1978, p. 275).

Assim, diferentemente dessas afirmações mecanicistas, Preobrazhensky destaca que a propriedade coletiva dos meios de produção não elimina a ação da lei do valor em seu interior. Os desafios e contradições colocados por essa compreensão demandaram ousadia por partes dos revolucionários russos a partir de 1917. Mais do que uma interpretação sobre a realidade capitalista, colocava-se perante eles a necessidade de iniciar o processo de construção de uma nova sociedade. Nas obras de Marx e Engels não há uma produção extensiva sobre como se organizaria a sociedade comunista e de que forma se daria a transição entre o capitalismo e o comunismo. Isto se relaciona com a própria metodologia de Marx, onde não haveria como produzir um modelo pronto a ser posto em prática, mas sim uma construção histórica processual, que se relacionaria com a realidade - e não adviria da teoria - do contexto determinado em que a revolução ocorresse.

Por fim, é interessante observar o peso que ganha, quando do debate teórico sobre a análise da realidade soviética do período, a realidade das relações de produção, especificamente das relações de trabalho. Em outros textos Preobrazhensky chega a afirmar que o momento em que houvesse uma transição da remuneração individual para a coletiva seria tão importante para o processo de transição ao socialismo quanto o momento de socialização dos meios de produção havia sido. $\mathrm{Ou}$ seja, é possível identificar uma importância analítica, e também de apontamento para ação política e econômica, visto que aqueles não eram debates meramente acadêmicos, da modificação da forma como a produção se estruturava até então, a qual ainda carregava em si as marcas da lei do valor.

Dessa forma, considero ser possível identificar na utilização de Preobrazhensky das categorias de Marx e de sua reinterpretação frente à realidade soviética, uma negação, mesmo que inicial, de uma compreensão 
mecanicista da evolução da história. E a abertura para se inserir debates sobre a ação dos sujeitos na história - tema que se relaciona ao debate democrático empreendido pela Oposição de Esquerda existente na URSS durante a década de 20, a qual Preobrazhensky integrou, e cuja teoria econômica, assim, integrava-se a um programa de transição ao socialismo de forma mais geral.

\section{Referências bibliográficas}

BETTELHEIM, Charles. A luta de classes na União Soviética. Primeiro período (1917-1923). Rio de Janeiro: Paz e Terra, 1979.

. Las luchas de clases en la URSS. Segundo periodo (1923-1930). Madrid: Siglo Veintiuno Editores, 1978.

DAY, Richard. B. Preface. In: DAY, Richard B.; GORINOV, Mikhail M. (Ed.) The Preobrazhensky papers. Archival documents and materials v. I: 1886-1920. Boston: Brill, 2014.

. Preobrazhensky and the Theory of the Transition Period. Soviet Studies, v. 27, n. 2, pp. 196-219, Apr. 1975.

DEUTSCHER, Isaac. O profeta desarmado. Rio de Janeiro: Civilização Brasileira, 1968.

FILTZER, Donald A. E. A. Preobrazhensky and the theory of expanded reproduction in the USSR during the period of primitive socialist accumulation. Ph. D. thesis - Institut of Soviet and East European Studies, University of Glasglow, 1976.

. Introduction. In: PREOBRAZHENSKY, E. A. The crisis of soviet industrialization. New York: The Macmillan Press LTD, 1980.

GORINOV, M. M. Foreword. In: DAY, Richard B.; GORINOV, Mikhail M. (Ed.). The Preobrazhensky papers. Archival documents and materials v. I: 1886-1920. Boston: Brill, 2014.

GORINOV, M. M.; TSAKUNOV, S. V. Life and works of Evgeny Alekseevich Preobrazhensky, Slavic Review, 50, 2, pp. 286-96, 1991.

HOWARD, M. C.; KING, J. E. A history of Marxian economics v. I, 18831929. Princeton University Press: Princeton, 1989.

MARX, Karl. Grundrisse. São Paulo: Boitempo, 2011b.

O capital: crítica da economia política: Livro I: o processo de produção do capital. São Paulo: Boitempo, 2013.

. O capital: crítica da economia política: Livro II: o processo de circulação do capital. São Paulo: Boitempo, 2014.

. O capital: crítica da economia política: Livro III: o processo global da produção capitalista. São Paulo: Boitempo, 2017.

MILLAR, James R. A note on primitive accumulation. in Marx and Preobrazhensky. Soviet Studies, v. 30, n. 3, pp. 384-93, Jul. 1978. 
MUSTO, Marcello. Karl Marx's Grundrisse. Foundations of the critique of political economy 150 years later. New York: Routledge, 2008.

NOVE, Alec. An economic history of the USSR 1917- 1991. Penguin Books: London, 1969.

PREOBRAJENSKI, E. A. A nova econômica. Rio de Janeiro: Paz e Terra, 1979.

. Autobiography (1886-1916). In: DAY, Richard B.; GORINOV, Mikhail M. (Ed.) The Preobrazhensky papers. Archival documents and materials v. I: 1886-1920. Boston: Brill, 2014a. . The new economics. Oxford: Oxford University press, 1965.

Como citar:

FREITAS, Rebecca de Oliveira As categorias marxistas no pensamento de Preobrazhensky: notas sobre uma teoria de transição. Verinotio - Revista on-line de Filosofia e Ciências Humanas, Rio das Ostras, v. 25, n. 1, pp. 252-83, abr. 2019.

Data de envio: 28 ago. 2018

Data de aceite: 20 fev. 2019 